\title{
Cheongsam Custom Network Pricing Analysis
}

\author{
Yuemei $\mathrm{GaO}^{1, \mathrm{a}}$, Xiaohui $\mathrm{Li}^{2, \mathrm{~b}}$
}

${ }^{1}$ Jiangxi Science \& Technology Normal University, Art College, Nanchang, Jiangxi, 330013

${ }^{2}$ Beijing Institute of Fashion Technology, School of Art and Engineering, Beijing,100029

${ }^{\mathrm{a}}$ email, ${ }^{\mathrm{b}}$ email

\section{Keywords: Cheongsam; Customized Network; Pricing Analysis}

\begin{abstract}
With the development of modern society, people's aesthetic ideas from the original retro fashion into the United States, the prevalence of cheongsam in the Republic of filling out the characteristics of Chinese female beauty, cheongsam Chinese culture is unique, it demonstrated the Chinese women's curves, cheongsam is also the Chinese women's traditional dress, to be known as the quintessence of China, China's national dress, it has a long cultural history, which show a gorgeous color Chinese clothing culture, this article introduces the cheongsam dress size of the market and cultural history of cheongsam industry, market supply and demand situation cheongsam, cheongsam analysis of market conditions and business dress into the networks and network pricing.
\end{abstract}

\section{Introduction}

Cheongsam, the unique charm of oriental women show traditional clothing Oriental female body, originated in China, known as China's national costume and quintessence of its three Chinese quintessence of Peking Opera, Chinese painting, Chinese belong to the same cultural legacy, but not opera , painting, traditional Chinese medicine so famous, is synonymous with Chinese cheongsam dress culture, but also the pride of the Chinese nation in the world dress culture is also a bright pearl.

We usually speak cheongsam dress generally refers to the Republic of emergence, but also refers to a small part of overall plans "banner Robe" in the Qing Dynasty, or "flag female Robe," including, but specific to distinguish what belongs to the era of dress in cheongsam There are many academic circles theory, can be described as different opinions, learn to dress people know cheongsam once during the Cultural Revolution and "letters, capital repair" is defined as the "four olds" at the time people can not talk about cheongsam, indeed talk cheongsam mere mention of a time study of people wear cheongsam and also make fewer even once be disabled until after the Cultural Revolution academic dress only slowly in the recovery of our country up until now research people are not cheongsam interrupted. China's "Ci Hai" interpretation of the cheongsam is this: "cheongsam, the former as a garment worn by women in the Qing Dynasty, the two sides do not slits, Sleeve eight inches to a foot, the edges are embroidered clothes color green. after the Revolution of Han women accepted and modified as follows: straight collar, Xie Jin and right opening, tight waist, long clothing to the knee, side slits, cuffs received little this is a detailed and comprehensive explanation of the cheongsam, the cheongsam. the features put in place.

\section{History of Cheongsam}

The initial formation of the cheongsam in the 1920s, some experts believe that history can be traced back cheongsam Qin and Han era, after the Republic of China is the most prevalent in 1920s clothing, as determined by the ROC government representative national dress in 1929, after the 1950s, the development of inland cheongsam gradually decline during the cultural Revolution is regarded as "feudal dross," "bourgeois sentiment" suffered criticism in the late 1980s resurgence of traditional culture in the interior, in the film industry, fashion and beauty events have brought a great response, not only cheongsam gradual revival in inland around the world are in a unique fashion. In 1984, Chinese women cheongsam is a specific diplomatic dress, 1990 Beijing Asian 
Games, whether on the mainland or the previous Olympics, Asian Games and the international nature of the conference or expo have chosen cheongsam with Chinese characteristics as a ceremonial clothing, and it was approved by the State Council announced in May 2011 cheongsam handmade craft is one of the third batch of national intangible cultural heritage. Chinese cheongsam will be set up in March 2014, now honorary president of our mother country Peng Liyuan. The 22nd APEC meeting in November 2014 held in Beijing China government as clothing cheongsam participating countries leading lady.

\section{The Characterized in Cheongsam}

China's traditional, classic cheongsam usually straight lines, loose clothing and body, both sides of the split, chest waist size ratio is closer degree of dress. This is the general characteristics of the cheongsam, the general performance characteristics of its appearance, right Ren also said dajin dajin cardigan clothes are generally semi-cardigan or cardigan form, usually collar collar plate New York, put the clothes to the side slits design, clothes are only a single piece of cloth instead of using two-piece or multi-piece of cloth, clothing with long sleeves in the flat cutting and so on. These are to be tailored according to the physical characteristics of each person, because each person's body structure is not the same, some large waist shoulder width, so that the design would have widened their shoulders and waist scale, some would have to increase its belly belly is too large parts of the design. Chinese cheongsam dress has the same thing with the West effect is to do the maximum expression of people's body image, try to oriental women's curves to show up.

\section{The Significance of Network Customized}

In the 21st century information age, the development of the Internet economy has played a significant role in many modern businesses have adopted the ways of network marketing, this approach not only optimizes the sales process and convenient for consumers, for businesses to stay at home to sell their goods, so that consumers can stay at home picked and chose to buy themselves satisfied with the goods, this marketing method not only increase sales but also improved sales, largely reflecting the network Times to bring many people's lives convenient, this way allows consumers to easily buy the right to own goods, cheongsam network largely customized to meet the needs of consumers, the current scientific and technological talent mining usefulness to the greatest extent of the network, allowing network services in person, online custom sales methods through the Internet for the needs of the customer and product technical parameters customized merchandise, network customization, and many emerging disciplines like, mostly by businesses network customized approach, the apparel industry is no exception, is in Chinese cheongsam with Chinese characteristics clothing United States, many consumers do not want to look around for the right to buy their dress can tailor your favorite style of dress, so at this point the consumer will need to dress this network customized network services, network customization is a marketing tool, customized network performance in the marketing aspects of marketing can produce a variety of effects, such as to enhance the brand value, strengthen businesses and customers coordination and communication between the network is a tool of foreign propaganda, future trends stage cheongsam market faces enormous opportunities and challenges, network customization cheongsam is a new period in the patterns and trends.

Since making cheongsam is a producer of high-level requirements, the choice of materials from the cheongsam, fabric open board on the lines of the design, collar, placket, cuffs, skirt and other aspects of the design details require producers with a very high level of technology it will be difficult to produce a suitable dress. It is because of the stringent technical requirements of production cheongsam, it will make the dress very few people, only in big cities and some of the higher level of consumption of the population in order to have cheongsam producer living space. It is also because of this, many small cities or economically underdeveloped areas cheongsam produced little or no longer exists. Since the dress is the quintessence of many women are able to wear cheongsam and feel proud and pride. In the era of the traditional developed even if the money 
you want to wear a dress can not be achieved, because no one will do cheongsam. But with the development of technology, the popularity of the network, people can stay at home through the Internet technology to meet their needs. Some will be produced cheongsam tailor technology through the Internet to audiences introduce ourselves to the community to promote themselves, while those who want to make the cheongsam is also a good chance via the Internet to order dress maker, will own data physical characteristics required to send the same Internet cheongsam producer, so you can make custom cheongsam producers and people do not dress together or through the producer and customization can be done to meet people. According to custom producer who transmitted data, it will be designed to be able to send the finished product to a qualified person customized by courier.

\section{Cheongsam Network Pricing Analysis}

Now online shopping has become the trend of the times, online shopping will not be an embarrassing joke, now popular word you may not know the word but you will not be able to online shopping, online shopping which shows the impact on our lives. The same is true in real life, cheongsam Internet Pricing has become a key link in the network cheongsam industry. Network pricing and the reality of commodity pricing is the same, in which the Internet Pricing cheongsam to consider the following factors: first, the need to customize custom cheongsam material; material is the basis for the production of dress, without the material it is impossible to produce a complete cheongsam, however, a different material is a far cry from its price, the price difference can be several times because the required raw material is different at different prices. Second, the production of the desired size cheongsam, which is the size; a fabric with a cloth adults require child needs is completely different. How much desired fabric also determines the cost they need. To this end, cheongsam pricing influenced by many factors.

With the continuous improvement of people's living standards, people's lives the most demand is getting higher and higher, the pursuit of beauty is a woman's self-willed is the heart of beauty in everyone, as the quintessence of the dress can show the charm of oriental woman head . With the development of modern network cheongsam custom network development model will become increasingly common, cheongsam network development channels will also be more and more open.

\section{Acknowledgements}

Jiangxi Science \& Technology Normal University Dr. Research Fund Project "Film Industry in China since the Reform and Opening and Countermeasures."

\section{References}

[1] Zeng Xiaoying. Republic cheongsam patterns analyzed at the Art Deco influence; modern decor (theory); 2015, 08.

[2] Bao Minxin, Ma Li. Chinese cheongsam; Shanghai Culture Publishing House; 2008

[3] Hugh•Jenkin•Jones. Chen Weiru translated. fashion design course; Intellectual Property Publishing House; China Water Power Press, 2006.

[4] Li Yinan. Chinese and Western beauty: art design cheongsam Republic of China; the United States with the times; in 2003, 11. 